\title{
US panel disagrees on cancer testing method
}

Washington. A US National Research Council committee on risk assessment methodology is divided over the continued use of a controversial testing procedure in which animals are exposed to massive doses of a chemical to determine whether it causes cancer.

In a report* released last week, the committee acknowledged limitations in the information provided by bioassays that use the maximum tolerated dose (MTD), the highest dose of a chemical compound that can be administered to a test animal without seriously affecting its health from causes other than cancer. But a majority of its members agreed that more data are needed before MTD testing can be replaced with a radically new approach.

Six of the committee's 17 members disagreed with that conclusion and called for a new approach to carcinogenicity testing. The committee minority recommended that the MTD bioassay be replaced as the initial test of a chemical's carcinogenicity with studies aimed at determining the physiological and metabolic mechanisms by which a chemical causes toxicity in animals. A panel of experts would then set dose levels for the animal bioassays based on these data - an approach that, the minority argues, would yield results more relevant to humans.

The use of the MTD has long been controversial. Critics argue that the sensitivity level for MTD testing has been set too high and that the number of chemicals tested by this method and found to be carcinogenic is so large that attention is being focused unnecessarily on chemicals that pose only insignificant risk to humans.

"The screen is supposed to narrow down the materials on which you would focus further attention", says Richard Reitz of the Dow Chemical Company, a committee member who sides with the minority. Reitz says that it is not very useful when about half the materials tested by this method are identified as animal carcinogens.

It is also argued that MTD bioassays provide little information on what happens at low doses and that at the MTD some chemicals induce cancer through mechanisms that do not occur at lower doses. "When we have mechanistic data at the molecular level, these data should be the driving force behind the long-term carcinogenicity studies", says Michael Gallo, associate dean for research at the Robert Wood Johnson Medical School, University of Medicine and Dentistry of New Jersey, and a committee member who also holds the minority view. Gallo says that he hopes the report is not read as an endorsement of "business as usual for another decade".

Opposing Gallo and Reitz is Bernard Goldstein, director of the Environmental and Occupational Health Sciences Institute at the Robert Wood Johnson Medical School and Rutgers University, and chair of the committee. MTD is needed because of a lack of a basic understanding on how chemicals work and the absence of appropriate testing procedures, he says.

Despite this disagreement, the majority recommended that the MTD should continue to be one of the doses used in carcinogenicity bioassays, although other doses downward from MTD/2 possibly to MTD/10 or less should be included. The report states "that there are as yet no validated mechanisms of carcinogenicity that support lowering the MTD and that failing to use the MTD for carcinogen screening will reduce the sensitivity of the bioassay and diminish the opportunity to compare results among chemicals and species". The majority believes that no additional tests related to carcinogenicity would normally be required if bioassays that include the MTD do not produce cancers in test animals.

Developed in the late 1960 s and early 1970s, animal-testing methods using the MTD have been standard in the United States for more than 15 years. In these bioassays, groups of 50 or more animals are usually tested at two or more doses of a chemical, with the highest dose being the MTD. Because the animals are exposed to the chemical for most of their lives, rodents with relatively short lifespans of two to three years are generally the preferred test species.

Diane Gershon

* Issues in Risk Assessment Committee on Risk Assessment Methodology, Board on Environmental Studies and Toxicology, Commission on Life Sciences National Academy Press, Washington DC, 1993 (ISBN 0-309-04786-2)

\section{William Petty papers purchased for $£ 1$ million}

London. The collected papers of one of the most influential but least familiar participants in the scientific revolution of the seventeenth century, the economist and polymath William Petty, have been purchased by the British Library for more than $£ 1$ million - a record sum for a historical figure of the period.

Petty is credited as the inventor of the science of statistics and is best known for his studies of the population of seventeenth-century London. Such work has led individuals ranging from Karl Marx to Maynard Keynes to regard him as the father of political economy.

But Petty, who trained as a doctor and later became a founding members of Britain's Royal Society, was also an intensely practical man. His ground-breaking survey of Ireland for Oliver Cromwell, resulting in 103 large-scale maps known as the "Down Survey", is seen as one of the milestones in modern cartography (as well as one of the first practical applications of the "scientific method" described by Francis Bacon). He also outlined plans for the first

catamaran - which

he described as a

"double-bottom" boat.

Petty has

remained in the shadows partly because his descendants have allowed scholars very restricted access to his papers. The

British Library

received a grant of

$£ 700,000$ from the

National Heritage Memorial Fund to buy the papers from his descendant, Lord Shelburne. The total cost is thought to be about $£ 1$ million.

Peter Barber, a map specialist at the library, says that the price paid for the Petty papers "reflects the importance that we attach to them". They are expected to throw light on both the origins of economic theory and statistics, as well as on the history of Anglo-Irish relations.

David Dickson

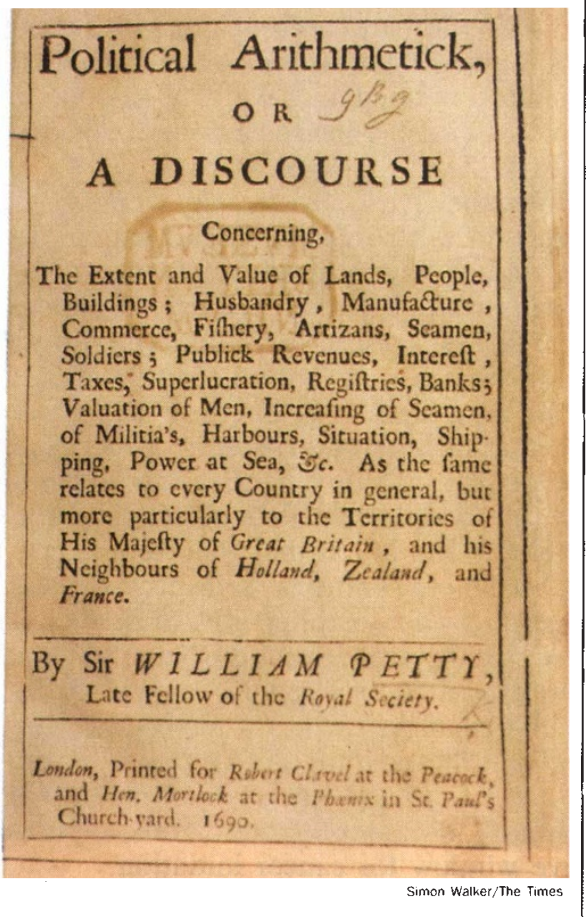

